\title{
Prediction of 11-year incidence of psychophysically dependent status or death among community-dwelling younger elderlies: from an age-specified community- based cohort study (the NISSIN project)
}

\author{
Satoe Okabayashi ${ }^{1 *}$, Takashi Kawamura ${ }^{1}$, Hisashi Noma ${ }^{2}$, Kenji Wakai ${ }^{3}$, Masahiko Ando ${ }^{4}$, Kazuyo Tsushita ${ }^{5}$,
} Hideki Ohira ${ }^{6}$, Shigekazu Ukawa ${ }^{7,8}$ and Akiko Tamakoshi ${ }^{8}$

\begin{abstract}
Background: Predicting adverse health events and implementing preventative measures are a necessary challenge. It is important for healthcare planners and policymakers to allocate the limited resource to high-risk persons. Prediction is also important for older individuals, their family members, and clinicians to prepare mentally and financially. The aim of this study is to develop a prediction model for within 11-year dependent status requiring long-term nursing care or death in older adults for each sex.

Methods: We carried out age-specified cohort study of community dwellers in Nisshin City, Japan. The older adults aged 64 years who underwent medical check-up between 1996 and 2005 were included in the study. The primary outcome was the incidence of the psychophysically dependent status or death or by the end of the year of age 75 years. Univariable logistic regression analyses were performed to assess the associations between candidate predictors and the outcome. Using the variables with $p$-values less than 0.1 , multivariable logistic regression analyses were then performed with backward stepwise elimination to determine the final predictors for the model.

Results: Of the 1525 female participants at baseline, 105 had an incidence of the study outcome. The final prediction model consisted of 15 variables, and the c-statistics for predicting the outcome was 0.763 (95\% confidence interval [Cl] 0.714-0.813). Of the 1548 male participants at baseline, 211 had incidence of the study outcome. The final prediction model consisted of 16 variables, and the c-statistics for predicting the outcome was 0.735 ( $95 \% \mathrm{Cl} 0.699-0.771)$.
\end{abstract}

Conclusions: We developed a prediction model for older adults to forecast 11-year incidence of dependent status requiring nursing care or death in each sex. The predictability was fair, but we could not evaluate the external validity of this model. It could be of some help for healthcare planners, policy makers, clinicians, older individuals, and their family members to weigh the priority of support.

Keywords: Aged, Cohort studies, Death, Forecasting, Nursing care

\footnotetext{
* Correspondence: okabayashi.satoe.8c@kyoto-u.ac.jp

${ }^{1}$ Kyoto University Health Service, Yoshida-Honmachi, Sakyo-ku, Kyoto 606-8501, Japan

Full list of author information is available at the end of the article
}

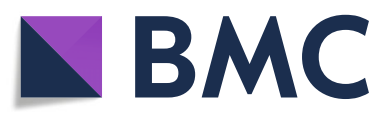

(0) The Author(s). 2021, corrected publication 2021. Open Access This article is licensed under a Creative Commons Attribution 4.0 International License, which permits use, sharing, adaptation, distribution and reproduction in any medium or format, as long as you give appropriate credit to the original author(s) and the source, provide a link to the Creative Commons licence, and indicate if changes were made. The images or other third party material in this article are included in the article's Creative Commons licence, unless indicated otherwise in a credit line to the material. If material is not included in the article's Creative Commons licence and your intended use is not permitted by statutory regulation or exceeds the permitted use, you will need to obtain permission directly from the copyright holder. To view a copy of this licence, visit http://creativecommons.org/ licenses/by/4.0/. The Creative Commons Public Domain Dedication waiver (http://creativecommons.org/publicdomain/zero/1. 0/) applies to the data made available in this article, unless otherwise stated in a credit line to the data. 


\section{Background}

Aging is one of the most urgent and important issues in the world. Life expectancy at birth is estimated to increase from 71.9 years in 2015-2020 to 76.9 years in 2045-2050 [1], and the estimated proportion of people over 65 years of age will increase from 8.3\% in 2015 to $17.8 \%$ in 2060 globally [1]. Aging in Japan is no exception. The proportion of people over 65 years of age is rapidly increasing year by year and will reach $30 \%$ of the total population by 2025 [2]. Because such a rapid increase in life expectancy has not been experienced until now, accommodation to the situation is important to provide better support to older individuals.

Predicting adverse health events and implementing preventative measures are a necessary challenge [3]. It is important for healthcare planners and policymakers to allocate the limited resource to high-risk persons [4]. Prediction is also important for older individuals, their family members, and clinicians to prepare mentally and financially $[4,5]$.

Prediction models for dysfunction or mortality among community-dwelling older individuals using health indicators have been previously reported [6-9]. A prediction scale to anticipate one's dependent status requiring longterm nursing care was also developed in Japan [10, 11]. However, previous models had two structural limitations. First, these models were constructed based on adults across a wide age range at baseline, where age was the overwhelming factor for mortality prediction compared with any other factors in older adults. In addition, the risk factors were sometimes different between older adults and younger adults [7]. Second, regarding the models predicting one's dependent status, only a single common model was constructed for both men and women. Since there are many gender differences in risk factors for mortality and adverse health events $[12,13]$, then, a prediction model at the specified age in each sex is needed.

Most Japanese employees retire from their jobs before 65 years of age, and this makes their big lifestyle change. In addition, the death rate accelerates after 65 years of age [14], even in Japan, a country with the highest rate of longevity $[15,16]$. Therefore, the purpose of this study is to develop a model for each sex to predict within 11year dependent status requiring long-term nursing care or death in older adults using comprehensive medical data from check-ups at age 64 years, one of the key ages for one's life.

\section{Methods}

\section{Study population}

The study population was extracted from the New Integrated Suburban Seniority Investigation (NISSIN) project, a community-based prospective cohort study of Japanese adults of the specified age. Project rationale and design are described elsewhere [17]. Residents of Nisshin City in Aichi Prefecture, Japan, who were 64 years of age on January 1 of the respective years from 1996 through 2005, were invited to undergo a free-ofcharge comprehensive medical check-up [17].

A total of 3073 participants (1548 men and 1525 women, $43.9 \%$ of the eligible community residents) who provided informed consent to the study were enrolled in the cohort. They were further invited to undergo the comprehensive medical check-up at age 70 years from 2002 through 2011. The participants have been followed by the second medical check-up, home visits by the municipal public health nurses, the public insurance system for long-term nursing care, or the vital statistics. The subjects of this study were those who participated in the medical check-ups and did not require any long-term nursing care age at 64 years.

\section{Health check-ups}

The health check-up data consisted of laboratory testing and a self-administrated questionnaire. The laboratory testing included physique (height and weight), blood pressure, and blood tests (blood count, liver function, kidney function, and glucose and lipid metabolism). The self-administered questionnaire included their present illnesses, past medical history, family medical history, competence in daily living (Tokyo Metropolitan Institute of Gerontology Index of Competence [TMIG-IC]) [18], depressive tendency (shorter version of the Geriatric Depression Scale [GDS]) [19, 20], mental stress or strain, life satisfaction status (life satisfaction index-K) [17, 21], and lifestyles (eating habits, alcoholic beverage intake, smoking habits, physical activity, sleeping habits, current work, level of participation in community activities, highest level of education, marital status, number of family members living together, and living place). The number of pregnancies, deliveries, and abortions; age at menarche and menopause; birth control use; and hormone replacement therapy-related questions were asked only to women.

\section{Long-term nursing care in Japan}

The government of Japan implemented a public insurance system for long-term nursing care in 2000 for general citizens aged 65 years or more and handicapped citizens aged 40 years or more [22]. When an insured person applies to use any nursing service, they are graded into support-demand level 1 to 2 or caredemand level 1 to 5 by the municipal board assessing the physical and mental conditions [22]. Here, support level 1 is the lowest, and care level 5 is the highest for nursing care. To those in care level 2 or higher who were deemed to need nursing care, $\geq 50$-minute support of daily activities such as bathing, defecation, cloth 
changing, and feeding, or medical treatment (drug administration, tracheal suctioning, and treatment for pressure sores) is provided at the designated frequency.

\section{Predictors and outcomes}

The predictor variables were selected from the data from the health check-ups at age 64 years. The outcome variable was the incidence of the psychophysically dependent status designated as care demand level 2 or higher of the public insurance system (composite outcome) or death of any cause by the end of the year of age 75 years. Outcomes were obtained from the vital statistics or through the insurance system.

\section{Statistical analyses}

We constructed a prediction model in each sex separately. The participants who moved out from Nisshin City without changing to a dependent status of care demand level 2 or more by the end of the year of age 75 years were excluded from the analyses.

In order to develop the prediction model, we first examined the association between each predictor and the outcome using a univariable logistic regression model. Cutoff points of the respective continuous variables were determined by the Youden Index [23]. Nominal and ordinal variables were substituted in the model as the dummy variable of their original categories. Variables with a $p$-value $\leq 0.1$ were prescribed, but the variables considered clinically irrelevant were excluded from the model. Variables with three or more categories were binarized after checking their dose-response relationship. The multivariable prediction models were then constructed by backward stepwise elimination to determine the final predictors for the more parsimonious model. The receiver-operating characteristic (ROC) curves were drawn, and the $c$-statistics were calculated. In addition, calibrations for the prediction models were conducted using the calibration plot and the HosmerLemeshow test. Finally, we performed Harrell's bootstrap bias corrections to adjust for the optimisms of the discriminant measures of the prediction models via 3600 bootstrap resampling [24].

Statistical analyses were conducted using STATA 15.0 (StataCop, College Station, TX, USA) and R ver. 3.5.1 (R Foundation for Statistical Computing, Vienna, Austria).

\section{Ethical considerations}

For informed consent, an opt-out approach was used from 1996 through 2001, and individual written informed consent was obtained thereafter [17, 25]. The study was approved by the Ethics Committees of Nagoya University Graduate School of Medicine, the National Center for Geriatrics and Gerontology of Japan, Aichi
Medical University, and Hokkaido University Graduate School of Medicine.

\section{Results \\ Women}

Of the 1525 female participants in the medical check-up at age 64 years, we excluded 106 women who moved out without becoming legal dependents by the end of age 75 years from the analyses. Baseline characteristics of the participants are shown in Table 1 . Less than $5 \%$ of the female participants had a medical history of severe diseases such as cancer and myocardial infarction. Their competence of daily living was relatively good based on the TMIG score [26]. Among the 1419 eligible female participants, 105 had an incidence of the outcome variables (60 died and 45 developed a dependent living status).

Risk or preventive factors associated with the outcome in univariable logistic regression analyses with $p \leq 0.1$ included 27 variables (Supplementary table 1 ). The tentative risk factors included the test result of systolic hypertension, erythrocytosis, higher alanine transaminase (ALT) level, higher serum creatinine level, and hypertriglyceridemia; a present diagnosis of diabetes mellitus; past history of otolaryngological diseases, stroke, hepatitis, and arthritis including rheumatoid arthritis; and lifestyles of alcoholic beverage intake, current smoking, skipping breakfast and midnight snack eating, preference of salty tastes, a slow gait, longer daily sleeping, and frequent night-time awakening. The tentative protective factors included higher body mass index (BMI), past history of cystitis, higher TMIG-IC, life satisfaction, full/various amount of eating, every day/ often snacking, routine exercise, and engagement in a hobby group.

The final multivariable prediction model consisted of 15 variables with $p<0.05$, including several items from the test results (BMI $\geq 22.6 \mathrm{~kg} / \mathrm{m}^{2}$, systolic blood pressure $\geq 156 \mathrm{~mm} \mathrm{Hg}$, hemoglobin $\geq 14.5 \mathrm{mg} / \mathrm{dl}$, ALT $\geq 35.0 \mathrm{U} /$ $\mathrm{ml}$ ), past medical history (otolaryngological diseases, stroke, and cystitis), a family medical history of hypertension, life satisfaction index-K $\geq 4$, and some lifestyles (eating a full or moderate amount, alcoholic beverage intake, current smoking, slow gait, night-time awakening $\geq 3$ times, sleeping more than $8 \mathrm{~h}$ a day) (Table 2). The $c$-statistics for predicting the outcome was 0.763 (95\% confidence interval [CI] 0.714-0.813) (Fig. 1), and the final model had a satisfactory goodness of fit (Hosmer-Lemeshow statistic $p=0.93$ ). The optimism-adjusted $c$-statistics was 0.734 (95\% CI $0.685-$ $0.784)$.

\section{Men}

Of the 1548 male participants in the medical check-up at age 64 years, we excluded 103 men who moved out without becoming legal dependents by the end of age 75 
Table 1 Baseline characteristics of the eligible study participants

\begin{tabular}{|c|c|c|c|c|}
\hline & \multicolumn{2}{|l|}{ Women } & \multicolumn{2}{|l|}{ Men } \\
\hline & All participants & Missing & All participants & Missing \\
\hline & $n=1419$ & & $n=1445$ & \\
\hline \multicolumn{5}{|l|}{ Present illness } \\
\hline Hypertension, $n$ (\%) & $551(38.8)$ & $0(0.0)$ & $729(50.4)$ & $0(0.0)$ \\
\hline Hyperlipidemia, $n$ (\%) & $915(64.5)$ & $0(0.0)$ & $791(54.7)$ & $1(0.07)$ \\
\hline Diabetes mellitus, n (\%) & $106(7.5)$ & $0(0.0)$ & $205(14.2)$ & $2(0.14)$ \\
\hline \multicolumn{5}{|l|}{ Past medical history } \\
\hline Cancer, $n(\%)$ & $61(4.3)$ & $0(0.0)$ & $47(3.3)$ & $0(0.0)$ \\
\hline Myocardial infarction, $n(\%)$ & $9(0.63)$ & $0(0.0)$ & $32(2.2)$ & $0(0.0)$ \\
\hline Stroke, $n(\%)$ & $34(2.4)$ & $0(0.0)$ & $56(3.9)$ & $0(0.0)$ \\
\hline Hepatitis, n (\%) & $41(2.9)$ & $0(0.0)$ & $77(5.3)$ & $0(0.0)$ \\
\hline TMIG, median (IQR) & $13(12,13)$ & $8(0.56)$ & $12(11,13)$ & $6(0.42)$ \\
\hline Depressive mood, ${ }^{\mathrm{a}}$ median (IQR) & $4(2,5)$ & $10(0.70)$ & $3(1,5)$ & $9(0.62)$ \\
\hline Life satisfaction, ${ }^{\text {b }}$ median (IQR) & $5(4,7)$ & $9(0.63)$ & $5(4,7)$ & $10(0.69)$ \\
\hline Smoking, $n(\%)$ & & $0(0.0)$ & & $1(0.07)$ \\
\hline Current & $48(3.4)$ & & 457 (31.6) & \\
\hline Past & $68(4.8)$ & & $704(48.7)$ & \\
\hline Never & $1303(91.8)$ & & $283(19.6)$ & \\
\hline Alcoholic beverage intake (yes), $n(\%)$ & $284(20.0)$ & $0(0.0)$ & $990(68.5)$ & $1(0.0)$ \\
\hline Physical exercise, $n(\%)$ & & $1(0.07)$ & & $2(0.14)$ \\
\hline Seldom & $599(42.2)$ & & $567(39.2)$ & \\
\hline$<1 /$ week & $112(7.9)$ & & $146(10.1)$ & \\
\hline$\geq 1 /$ week & 707 (49.8) & & $730(50.5)$ & \\
\hline Final education & & $12(0.85)$ & & $6(0.42)$ \\
\hline Junior high school & $506(35.7)$ & & $415(28.7)$ & \\
\hline Senior high school & $679(47.9)$ & & $561(38.8)$ & \\
\hline Junior college or higher & $222(15.6)$ & & $463(32.0)$ & \\
\hline Marital status & & $12(0.85)$ & & $4(0.28)$ \\
\hline Presently married & $1181(83.2)$ & & $1374(95.1)$ & \\
\hline Never, widowed, or divorced & $226(15.9)$ & & $67(4.6)$ & \\
\hline
\end{tabular}

TMIG Tokyo Metropolitan Institute of Gerontology Index of Competence, IQR Interquartile range

${ }^{\mathrm{a}}$ The score of Geriatric Depression Scale

${ }^{\mathrm{b}}$ The score of Life Satisfaction Index-K

years from the analyses. Baseline characteristics of the participants are shown in Table 1 . Less than $5 \%$ of the male participants had a medical history of severe diseases such as cancer and myocardial infarction. Their competence of daily living was relatively good based on TMIG score [26]. Among the 1445 eligible subjects, 211 had an incidence of the outcome variables (172 died and 39 developed a dependent status).

Risk or preventive factors associated with the outcome in univariable logistic regression analyses with $p \leq 0.1$ included 36 variables (Supplementary table 2). The tentative risk factors included the test results of systolic and diastolic hypertension, higher ALT level, and higher serum creatinine level; a present diagnosis of diabetes mellitus; a past history of pulmonary tuberculosis or pleurisy, chronic bronchitis, hemorrhagic stroke, and hepatitis; a family medical history of stroke; depressive tendency; and lifestyles of frequent eating of snack/midnight snack, frequent eating dinner alone, preference of oily dishes, dietary restrictions by a physician, a slow gait, shorter walking time, daily car using, long time to fall asleep, current smoking, passive smoking, low level of education, unmarried status, living in residential/agricultural area, and shorter duration of living in the place. The tentative protective factors included erythrocytosis and hyper high-density lipoprotein cholesterolemia; a 
Table 2 Predictors for dependent status or death for the final prediction model (women)

\begin{tabular}{|c|c|c|c|c|c|c|}
\hline & Subjects & Outcome $^{a}$ & (\%) & $\beta$-coefficient & OR & $95 \% \mathrm{Cl}$ \\
\hline \multicolumn{7}{|l|}{ Laboratory testing } \\
\hline \multicolumn{7}{|l|}{ Physique } \\
\hline $\mathrm{BMI} \geq 22.6$ & 688 & 41 & $(6.0)$ & -0.81 & 0.44 & $0.28-0.70$ \\
\hline Systolic blood pressure $\geq 156 \mathrm{~mm} \mathrm{Hg}$ & 136 & 23 & $(16.9)$ & 1.19 & 3.30 & $1.88-5.79$ \\
\hline \multicolumn{7}{|l|}{ Blood test } \\
\hline Hemoglobin $\geq 14.5$ mg/dl & 62 & 11 & $(17.7)$ & 1.17 & 3.21 & $1.50-6.89$ \\
\hline ALT $\geq 35.0 \mathrm{U} / \mathrm{ml}$ & 82 & 11 & (13.4) & 0.77 & 2.16 & $1.03-4.52$ \\
\hline \multicolumn{7}{|l|}{ Questionnaire } \\
\hline \multicolumn{7}{|l|}{ Past medical history } \\
\hline Otolaryngological diseases & 180 & 20 & $(11.1)$ & 0.80 & 2.23 & $1.27-3.92$ \\
\hline Stroke & 34 & 9 & $(26.5)$ & 1.57 & 4.79 & $1.92-11.94$ \\
\hline Cystitis & 179 & 6 & (3.4) & -0.89 & 0.41 & $0.17-0.98$ \\
\hline \multicolumn{7}{|l|}{ Family medical history } \\
\hline Hypertension & 289 & 13 & $(4.5)$ & -0.68 & 0.50 & $0.26-0.96$ \\
\hline Life satisfaction index-K $\geq 4$ & 1069 & 66 & $(6.2)$ & -0.48 & 0.62 & $0.39-0.97$ \\
\hline Eating full or moderate amount & 638 & 38 & $(6.0)$ & -0.43 & 0.65 & $0.42-1.02$ \\
\hline Alcohol drinker & 284 & 29 & $(10.2)$ & 0.60 & 1.82 & $1.12-2.95$ \\
\hline Current smoker & 48 & 10 & $(20.8)$ & 1.25 & 3.50 & $1.56-7.84$ \\
\hline Slow gait & 196 & 28 & (14.3) & 0.97 & 2.63 & $1.56-4.45$ \\
\hline Night-time awakening $\geq 3$ times & 89 & 15 & $(16.9)$ & 1.01 & 2.75 & $1.45-5.22$ \\
\hline Daily sleeping $\geq 8 \mathrm{~h}$ & 265 & 29 & $(10.9)$ & 0.48 & 1.62 & $0.99-2.65$ \\
\hline Intercept & & & & -3.16 & & \\
\hline
\end{tabular}

$B M I$ Body mass index, ALT Alanine transaminase, OR Odds ratio, $\mathrm{Cl}$ Confidence interval ${ }^{\mathrm{a}}$ Death or dependent status of care demand level 2 or more

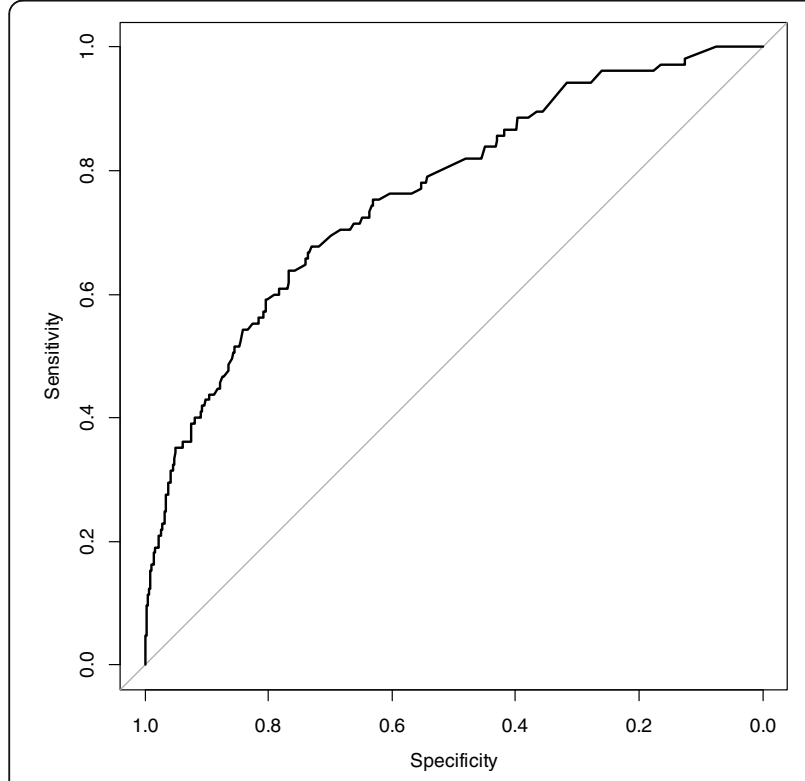

Fig. 1 The receiver-operating characteristic curve of the model to estimate the probability of dependent status/death (women) past history of gastroduodenal polyp; a family medical history of cancer or hypertension; life satisfaction; irregular dinner time; frequent eating out for lunch; preference of salty tastes; routine exercise; and participation in community activities (community events, visiting friends or relatives living in neighborhood).

The final model consisted of 16 variables with $p<$ 0.05 , including three items from the test results (systolic blood pressure $\geq 130 \mathrm{~mm} \mathrm{Hg}$, ALT $\geq 29.0 \mathrm{U} / \mathrm{ml}$, serum creatinine $\geq 0.9 \mathrm{mg} / \mathrm{dl}$ ), a present diagnosis of diabetes mellitus, past medical history (hemorrhagic stroke, and hepatitis), family medical history (hypertension or cancer), and some lifestyles (irregular dinner time, frequently eating snack/midnight snack once per week or more, preference of salty tastes, current smoking, a slow gait, long time to fall asleep [ $30 \mathrm{~min}$ or more], highest education of junior high school or lower, and unmarried status) (Table 3). The $c$-statistics for predicting the outcome variables was 0.735 (95\% CI 0.699-0.771) (Fig. 2), and the final model had a satisfactory goodness of fit (Hosmer-Lemeshow statistic $p=0.58$ ). The optimismadjusted $c$-statistics was 0.713 (95\% CI $0.677-0.748)$. 
Table 3 Predictors for dependent status or death for the final prediction model (men)

\begin{tabular}{|c|c|c|c|c|c|c|}
\hline & Subjects & Outcome $^{a}$ & (\%) & $\beta$-coefficient & OR & $95 \% \mathrm{Cl}$ \\
\hline \multicolumn{7}{|l|}{ Laboratory testing } \\
\hline \multicolumn{7}{|l|}{ Physique } \\
\hline Systolic blood pressure $\geq 130 \mathrm{~mm} \mathrm{Hg}$ & 972 & 165 & $(17.0)$ & 0.61 & 1.84 & $1.26-2.67$ \\
\hline \multicolumn{7}{|l|}{ Blood test } \\
\hline $\mathrm{ALT} \geq 29.0 \mathrm{U} / \mathrm{ml}$ & 269 & 57 & $(21.2)$ & 0.43 & 1.54 & $1.06-2.23$ \\
\hline Serum creatinine $\geq 0.9 \mathrm{mg} / \mathrm{dl}$ & 729 & 123 & $(16.9)$ & 0.46 & 1.58 & $1.15-2.18$ \\
\hline \multicolumn{7}{|l|}{ Questionnaire } \\
\hline \multicolumn{7}{|l|}{ Present illness } \\
\hline Diabetes mellitus & 205 & 47 & $(22.9)$ & 0.55 & 1.74 & $1.16-2.60$ \\
\hline \multicolumn{7}{|l|}{ Past medical history } \\
\hline Hemorrhage stroke & 17 & 7 & $(41.2)$ & 1.32 & 3.74 & $1.27-11.00$ \\
\hline Hepatitis & 77 & 21 & $(27.3)$ & 0.99 & 2.69 & $1.51-4.81$ \\
\hline \multicolumn{7}{|l|}{ Family medical history } \\
\hline Cancer & 560 & 62 & $(11.1)$ & -0.49 & 0.61 & $0.44-0.86$ \\
\hline Hypertension & 261 & 28 & $(10.7)$ & -0.52 & 0.60 & $0.38-0.94$ \\
\hline Irregular dinner time & 1196 & 186 & $(15.6)$ & -0.65 & 0.52 & $0.32-0.84$ \\
\hline $\begin{array}{l}\text { Frequently eating snack/midnight snack } \\
\text { once per week or more }\end{array}$ & 584 & 99 & $(17.0)$ & 0.38 & 1.47 & $1.07-2.02$ \\
\hline Preference of salty tastes & 1302 & 180 & $(13.8)$ & -0.69 & 0.50 & $0.31-0.80$ \\
\hline Current smoker & 457 & 94 & (20.6) & 0.72 & 2.05 & $1.48-2.84$ \\
\hline Slow gait & 175 & 44 & $(25.1)$ & 0.69 & 1.99 & $1.31-3.03$ \\
\hline Time to fall asleep ( $\geq 30 \mathrm{~min}$ ) & 175 & 38 & $(21.7)$ & 0.48 & 1.62 & $1.06-2.49$ \\
\hline Junior high school or lower level of education & 415 & 78 & $(18.8)$ & 0.30 & 1.35 & $0.97-1.89$ \\
\hline Divorced, widowed, or never married & 67 & 19 & $(28.4)$ & 1.14 & 3.12 & $1.73-5.65$ \\
\hline Intercept & & & & -2.56 & & \\
\hline
\end{tabular}

ALT Alanine transaminase, OR Odds ratio, Cl Confidence interval

${ }^{\mathrm{a}}$ Death and dependent status of care demand level 2 or more

\section{Discussion}

We developed and validated prediction models for 11year incidence of dependent status or death in each sex using comprehensive health check-up data and detailed self-administered questionnaire answers. To our knowledge, this is the first prediction model to forecast the prognosis of older adults, separated by sex. These models were fairly calibrated and predictive with a $c$ statistic of 0.763 in women and 0.748 in men. This model will be referred for the allocation of the resources to high-risk persons if the model will be spreading use in the society. The older adults using this model can also prepare for their future based on the result.

The strong points of this study are age and sex. First, all the participants were the same age, 64 years old at baseline. By focusing the subjects' age at 64 years, we could overcome the limitation of the previous studies that the age was widely distributed which strongly affected the incidence of outcomes. In addition to this, age of 64 years is just before a new stage in life such as retirement from the workforce and entrance into pension life. Vital statistics show that mortality and morbidity markedly increase around this age [14]. Adults of this age have to consider and plan for their subsequent life. Second, we constructed the prediction model separately by sex. The biological factors such as hormonal secretion and activity of cytokines [27, 28] and social factors including marital status and healthcare utilization are much different by sex $[28,29]$. Therefore, the prediction models constructed separately by sex are valuable.

This is the first long-term (more than 10 years) prediction model focusing on both psychophysically dependent status and death at the same time in community-dwelling older adults. Psychophysically dependent status requiring longterm nursing care is a heavy burden for older adults, their family members, and public health. Furthermore, a prediction focusing only on dependent status or dysfunction would miss the extreme dysfunction, that is death. If a medical treatment that can reduce the morbidity increased the mortality, the treatment would not be acceptable. Therefore, 


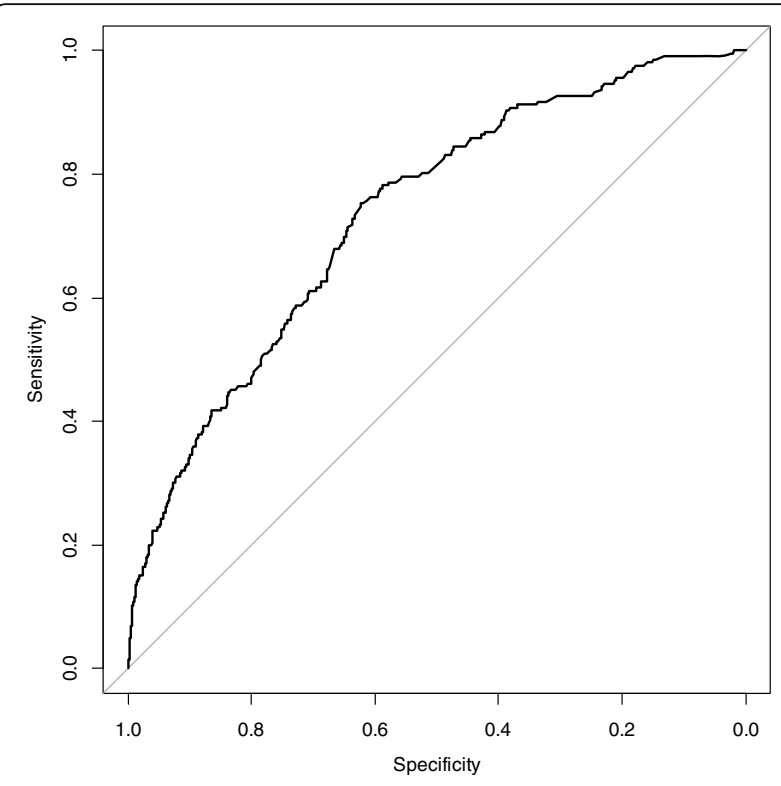

Fig. 2 The receiver-operating characteristic curve of the model to estimate the probability of dependent status/death (men)

our composite outcome, dependent status or death, is relevant for the prediction model of high-risk persons.

The predictability of our model was similar to the previous models that predict death or dysfunction [6, 7]. In general, age is the dominant factor in such kind of prediction models with the participants of wide age range because the death and dependent status strongly depended on the age [14]. Therefore, the predictability of our model with the participants of the same key age can be substantially good when we compare our model with former models constructed by the participants of wide age range. However, the variables used in our final models were somewhat different to those of previous models. The variables of lifestyle such as eating and sleeping habits were included in our model, which were modifiable by the persons' will. On the other hand, the variables often included in previous prediction models, such as a medical history of cancer and cardiovascular diseases, were statistically eliminated from our models. We consider that this is because the participants of our study are all community-dwelling 64-year-old people who are younger and healthier than those of previous studies, and the prevalence of these diseases was too low to detect any associations with the study outcome.

Interestingly, social factors such as marital and educational status were well associated with the outcome in men. It has been previously reported that living alone and eating alone would increase mortality, especially in men [30-32]. Marital status was also reported to be associated with frailty [29]. Older men who are divorced/widowed/ never married often live alone or eat alone, and these living states might induce unhealthy lifestyle and evoke adverse outcomes. In contrast, a high educational status would lead to a higher pension income, which could help assure routine disease screening and early treatment in men, the typical breadwinner of a family [33].

There are several limitations to the study. First, the dependent status requiring nursing care could be detected since 2000 when the insurance system for long-term nursing care was introduced in Japan. However, the citizens who developed a dependent status requiring long-term nursing care before 2000 were supposed to apply for the care or to die after 2000. Second, the judgment of care level is subjective. However, the standard for designation is made by the expert board in each municipality and expected to be fair and stable. Third, gene and blood substances which were potentially related to one's prognosis in older adults were not included in our prediction model. Some of them were already examined in our field [34]. However, it is more practical and feasible to construct models using data easily collected in daily practices. Fourth, only $43.9 \%$ of the eligible community residents participated in this study, and there must be some selection bias. Not a few residents who did not participate in the health check-up might have serious physical/mental condition or receive heavy medical care. However, we aimed to make a prediction model of dependent status or death for the old individuals without major social disabilities. Then, we guessed the participants would be more representative of our target population than the whole 64-year population. Fifth, this prediction model can be used only for Japanese participants aged 64 years. However, as we mentioned, the age 64 years is the key age of one's life, and we believe that this model is meaningful. Besides, we could not evaluate the external validity of this model so that external validation study in another cohort is the tasks in the future. Finally, more than 20 years have passed since the baseline data were collected. In particular, the information and communication technology has been tremendously developed in these decades, and the lifestyle of older adults has also been affected by such time trend. However, "out-ofdata" is inevitable for long-term cohort studies.

\section{Conclusion}

In conclusion, based on this age-specific communitybased cohort study, we have developed and validated a prediction model for older adults to predict 11-year incidences of death or dependent status requiring nursing care in each sex. Our model relies on 15 variables in women and 16 variables in men, which are available by health check-ups and a self-administered questionnaire. The predictive ability was fair in both sexes, and it could help healthcare planners, policymakers, clinicians, older individuals, and their family members to weigh the priority of support in the highly aged seniorities. 


\section{Abbreviations}

TMIG-IC: Tokyo Metropolitan Institute of Gerontology Index of Competence; GDS: Geriatric Depression Scale; ROC: Receiver-operating characteristic; ALT: Alanine transaminase; BMI: Body mass index; Cl: Confidence interval

\section{Supplementary Information}

The online version contains supplementary material available at https://doi. org/10.1186/s12199-021-00968-8

Additional file 1: Supplementary table 1. Potential predictors for dependent status or death by the end of the year of age 75 years in univariable logistic regression analyses (women)

Additional file 2: Supplementary table 2. Potential predictors for dependent status or death by the end of the year of age 75 years in univariable logistic regression analyses (men)

\section{Acknowledgements}

We thank the Health Center and Hygiene Department of Nisshin City for their cooperation.

\section{Authors' contributions}

SO contributed to the methodology, formal analysis, investigation, data curation, writing —original draft, visualization, and funding acquisition. TK contributed to the conceptualization, methodology, investigation, writing-original draft, supervision, and funding acquisition. HN contributed to the validation, formal analysis, data curation, and writing-original draft. KW, MA, KT, HO, and SU contributed to the design, acquisition of data, interpretation of data, critical review, and feedback. AK contributed to the design, acquisition of data, interpretation of data, supervision, project administration, funding acquisition, critical review, and feedback. All authors read and approved the final manuscript.

\section{Funding}

This work was supported by the JSPS KAKENHI [Grant Numbers JP15390197, JP26520105, JP20K02392] and Mitsui Sumitomo Insurance Welfare Foundation.

\section{Availability of data and materials}

The data set analyzed for the current study is not publicly available because we did not obtain informed consent from the participants for the data use by persons except the researchers of the NISSIN project.

\section{Declarations}

\section{Ethics approval and consent to participate}

As we have written in the methods, for informed consent, an opt-out approach was adopted from 1996 through 2001, and individual written informed consent was obtained thereafter. The study was approved by the Ethics Committees of Nagoya University Graduate School of Medicine, the National Center for Geriatrics and Gerontology of Japan, Aichi Medical University of Medicine, and Hokkaido University Graduate School of Medicine.

\section{Consent for publication}

Not applicable.

\section{Competing interests}

The authors declare that they have no competing interests.

\footnotetext{
Author details

${ }^{1}$ Kyoto University Health Service, Yoshida-Honmachi, Sakyo-ku, Kyoto 606-8501, Japan. ${ }^{2}$ Department of Data Science, The Institute of Statistical Mathematics, 10-3 Midori-cho, Tachikawa, Tokyo 190-8562, Japan. ${ }^{3}$ Department of Preventive Medicine, Nagoya University Graduate School of Medicine, 65 Tsurumai-cho, Showa-ku, Nagoya 466-8550, Japan. ${ }^{4}$ Center for Advanced Medicine and Clinical Research, Nagoya University Hospital, 65, Tsurumai-cho, Showa-ku, Nagoya 466-8550, Japan. ${ }^{5}$ Kagawa Nutrition University, 3-9-21 Chiyoda, Sakado city, Saitama 350-0288, Japan. ${ }^{6}$ Department of Psychology, Graduate School of Informatics, Nagoya University, Furo-cho, Chikusa-ku, Nagoya 464-8601, Japan. ${ }^{7}$ Research Unit of Advanced Interdisciplinary Care Science, Graduate School of Human Life Science, Osaka City University, 3-3-138, Sugimoto, Osaka, Sumiyoshi-ku
}

558-8585, Japan. ${ }^{8}$ Department of Public Health, Faculty of Medicine and Graduate School of Medicine, Hokkaido University, North 15, West 7, Kita-ku, Sapporo 060-8638, Japan.

Received: 9 December 2020 Accepted: 29 March 2021

Published online: 10 April 2021

\section{References}

1. United Nations Department of Economic and Social Affairs, Population Division. World population prospects, the 2017 revision, key findings and advance tables. 2017. https://population.un.org/wpp/Publications/Files/ WPP2017_KeyFindings. Accessed 17 Nov 2020.

2. Cabinet Office, Government of Japan. Situation on aging population, annual report on the aging society: 2018. 2018. https://www8.cao.go.jp/kourei/ whitepaper/w-2018/html/zenbun/s1_1_2.html. Accessed 17 Nov 2020.

3. Moons KG, Royston P, Vergouwe Y, Grobbee DE, Altman DG. Prognosis and prognostic research: what, why, and how? BMJ. 2009;338:b375. https://doi. org/10.1136/bmj.b375

4. Kurichi JE, Bogner HR, Streim JE, Xie D, Kwong PL, Saliba D, et al. Predicting 3-year mortality and admission to acute-care hospitals, skilled nursing facilities, and long-term care facilities in Medicare beneficiaries. Arch Gerontol Geriatr. 2017;73:248-56. https://doi.org/10.1016/j.archger.2 017.08.005

5. Brodaty $\mathrm{H}$, Connors $\mathrm{MH}, \mathrm{Xu}$ J, Woodward M, Ames D, PRIME study group. Predictors of institutionalization in dementia: a three year longitudinal study. J Alzheimers Dis. 2014;40(1):221-6. https://doi.org/1 0.3233/JAD-131850.

6. Yourman LC, Lee SJ, Schonberg MA, Widera EW, Smith AK. Prognostic indices for older adults: a systematic review. JAMA. 2012;307(2):182-92. https://doi.org/10.1001/jama.2011.1966.

7. Kusumastuti S, Rozing MP, Lund R, Mortensen EL, Westendorp RGJ. The added value of health indicators to mortality predictions in old age: a systematic review. Eur J Intern Med. 2018:57:7-18.

8. Schonberg MA, Li V, Marcantonio ER, Davis RB, McCarthy EP. Predicting mortality up to 14 years among community-dwelling adults aged 65 and older. J Am Geriatr Soc. 2017;65(6):1310-5. https://doi.org/10.1111/jgs.14805.

9. O'Caoimh R, Cornally N, Weathers E, O'Sullivan R, Fitzgerald C, Orfila F, et al. Risk prediction in the community: a systematic review of case-finding instruments that predict adverse healthcare outcomes in communitydwelling older adults. Maturitas. 2015;82(1):3-21. https://doi.org/10.1016/j. maturitas.2015.03.009.

10. Tomata Y, Hozawa A, Ohmori-Matsuda K, Nagai M, Sugawara Y, Nitta A et al. Validation of the Kihon checklist for predicting the risk of 1-year incident long-term care insurance certification: the Ohsaki cohort 2006 study. Nihon Koshu Eisei Zasshi. 2011;58(1):3-13.

11. Tsuji T, Takagi D, Kondo N, Kondo K. Development of risk assessment scales for needed support/long-term care certification: a longitudinal study using the Kihon checklist and medical assessment data (article in Japanese). Nihon Koshu Eisei Zasshi. 2017;64(5):246-57. https://doi.org/1 0.11236/jph.64.5_246.

12. Piackova E, Jäger B, Farhan S, Christ G, Schreiber W, Weidinger F, et al. Gender differences in short- and long-term mortality in the Vienna STEMI registry. Int J Cardiol. 2017;244:303-8. https://doi.org/10.1016/j.jijcard.2017.05.068.

13. Okabayashi S, Kawamura T, Wakai K, Ando M, Tsushita K, Ohira H, et al. Lifestyle and psychosocial factors and a decline in competence in daily living among Japanese early elderly people: from an age-specified community-based cohort study (NISSIN project). Environ Health Prev Med. 2019;24(1):28. https://doi.org/10.1186/s12199-019-0787-7.

14. Director-General for Statistics and Information Policy Ministry of Health, Labour and Welfare. Vital statistics in Japan, trends up to 2016 (in Japanese). 2018. https://www.mhlw.go.jp/toukei/list/dl/81-1a2.pdf. Accessed 17 Nov 2020.

15. Ukawa S, Tamakoshi A, Wakai K, Ando M, Kawamura T. Body mass index is associated with hypertension in Japanese young elderly individuals: findings of the new integrated suburban seniority investigation. Intern Med. 2015; 54(24):3121-5. https://doi.org/10.2169/internalmedicine.54.4702.

16. Organisation for Economic Co-operation and Development. Society at a Glance 2019. 2019. https://www.oecd-ilibrary.org/social-issues-migration-hea Ith/society-at-a-glance-2019_soc_glance-2019-en. Accessed 17 Nov 2020.

17. Kitamura T, Kawamura T, Tamakoshi A, Wakai K, Ando M, Ohno Y. Rationale, design, and profiles of the new integrated suburban seniority investigation 
(NISSIN) project: a study of an age-specific, community-based cohort of Japanese elderly. J Epidemiol. 2009;19(5):237-43. https://doi.org/10.2188/jea. JE20081026.

18. Koyano W, Shibata H, Nakazato K, Haga H, Suyama Y. Measurement of competence: reliability and validity of the TMIG index of competence. Arch Gerontol Geriatr. 1991;13(2):103-16. https://doi.org/10.1016/0167-4943(91 ) $90053-S$.

19. Burke WJ, Roccaforte WH, Wengel SP. The short form of the geriatric depression scale: a comparison with the 30-item form. J Geriatr Psychiatry Neurol. 1991;4:173-8.

20. Almeida OP, Almeida SA. Short versions of the geriatric depression scale: a study of their validity for the diagnosis of a major depressive episode according to ICD-10 and DSM-IV. Int J Geriatr Psychiatry. 1999; 14(10):858-65. https://doi.org/10.1002/(SICI)1099-1166(199910)14:10< 858::AID-GPS35>3.0.CO;2-8

21. Koyano W, Shibata H. Development of a measure of subjective well-being in Japan. In: Vellas BJ, Albarede L, editors. Facts and research in gerontology. Holmes Beach: Gaunt; 1994. p. 181-7.

22. Lin HR, Otsubo T, Imanaka Y. Survival analysis of increases in care needs associated with dementia and living alone among older long-term care service users in Japan. BMC Geriatr. 2017;17(1):182. https://doi.org/10.1186/ s12877-017-0555-8.

23. Youden WJ. Index for rating diagnostic tests. Cancer. 1950;3(1):32-5. https:// doi.org/10.1002/1097-0142(1950)3:1<32::AID-CNCR2820030106>3.0.CO;2-3.

24. Steyerberg EW, Harrell FE, Borsboom GJ, Eijkemans MJ, Vergouwe Y, Habbema JD. Internal validation of predictive models: efficiency of some procedures for logistic regression analysis. J Clin Epidemiol. 2001;54(8):77481. https://doi.org/10.1016/S0895-4356(01)00341-9.

25. Tamakoshi A, Kawamura T, Wakai K, Ando M. Written informed consent for participation in a study and reduction in consent rate. J Epidemiol. 2008; 18(6):291-4. https://doi.org/10.2188/jea.JE2008011.

26. Koyano W, Hashimoto M, Fukawa T, Shibata H, Gunji A. ffunctional capacity of the elderly: measurement by the TMIG index of competence] (article in Japanese). Nihon Koshu Eisei Zasshi. 1993;40:468-74.

27. DuPont JJ, Kenney RM, Patel AR, Jaffe IZ. Sex differences in mechanisms of arterial stiffness. Br J Pharmacol. 2019;176(21):4208-25. https://doi.org/1 $0.1111 / \mathrm{bph} .14624$

28. Gordon EH, Peel NM, Samanta M, Theou O, Howlett SE, Hubbard RE. Sex differences in frailty: a systematic review and meta-analysis. Exp Gerontol. 2017;89:30-40. https://doi.org/10.1016/j.exger.2016.12.021.

29. Staehelin K, Schindler C, Spoerri A, Zemp Stutz E, Swiss National Cohort Study Group. Marital status, living arrangement and mortality: does the association vary by gender? J Epidemiol Community Health. 2012;66(7):e22. https://doi.org/10.1136/jech.2010.128397.

30. Ng TP, Jin A, Feng L, Nyunt MS, Chow KY, Fong NP. Mortality of older persons living alone: Singapore longitudinal ageing studies. BMC Geriatr. 2015;15(1):126. https://doi.org/10.1186/s12877-015-0128-7.

31. Tani Y, Kondo N, Noma H, Miyaguni Y, Saito M, Kondo K. Eating alone yet living with others is associated with mortality in older men: the JAGES cohort survey. J Gerontol B Psychol Sci Soc Sci. 2018;73:1330-4.

32. Tanaka H, Miyawaki A, Toyokawa S, Kobayashi Y. Relationship of relative poverty and social relationship on mortality around retirement: a 10-year follow-up of the Komo-Ise cohort. Environ Health Prev Med. 2018;23(1):64. https://doi.org/10.1186/s12199-018-0756-6.

33. Singer $\mathrm{S}$, Bartels $\mathrm{M}$, Briest $\mathrm{S}$, Einenkel J, Niederwieser $\mathrm{D}$, Papsdorf $\mathrm{K}$, et al. Socio-economic disparities in long-term cancer survival-10 year follow-up with individual patient data. Support Care Cancer. 2017;25(5):1391-9. https://doi.org/10.1007/s00520-016-3528-0.

34. Kojima R, Ukawa S, Zhao W, Suzuki K, Yamada H, Tsushita K, et al. Association of adiponectin with cancer and all-cause mortality in a Japanese community-dwelling elderly cohort: a case-cohort study. J Epidemiol. 2018;28(8):367-72. https://doi.org/10.2188/jea.JE20170087.

\section{Publisher's Note}

Springer Nature remains neutral with regard to jurisdictional claims in published maps and institutional affiliations.

Ready to submit your research? Choose BMC and benefit from:

- fast, convenient online submission

- thorough peer review by experienced researchers in your field

- rapid publication on acceptance

- support for research data, including large and complex data types

- gold Open Access which fosters wider collaboration and increased citations

- maximum visibility for your research: over $100 \mathrm{M}$ website views per year

At BMC, research is always in progress.

Learn more biomedcentral.com/submissions 